\section{The MSA Undergraduate Scholarship Program}

The MSA Undergraduate Scholarship Program was initiated in 1988 to encourage students to pursue microscopy-related careers. Since its inception, the program has grown steadily and has provided support for over thirty undergraduate projects. Many awardees have continued their microscopy-oriented research and have gone on to graduate school, industry or teaching positions.

The program is open to senior and junior undergraduate students. The scholarship application includes a research proposal (including budget) witten by the student and letters of recommendation from a faculty member and a project advisor.

The response to the 1993 MSA Undergraduate Scholarship Program was outstanding in terms of quality and number of applicants. Twenty-three applications were received and an all time high of seven were approved for funding as follows:

Karen Backlas (Junior, University of Michigan)

"In Situ Characterization of Mo Oxides"

Steven Hardt (Junior, Massachusetts Institute of Technology) "Computer Analysis of EM Images of Biological Assemblies"

William Marsillo (Junior, Stevens Institute of Technology)

"Electron-Optical Imaging of Styrene-Butadiene Block. Copolymers"

Laurel Partin (Senior, New Mexico State University) "Development and Examination of Attachment Substrate for Sulfate Reducing Bacteria by TEM and Environmental SEM"

Ken Ring (Senior, University of California San Diego) "TEM Analysis of Ordering in the $\ln _{x} \mathrm{Ga}_{1-x}$ P/GaP System"

Conrad Simon (Junior, University of Tennessee) "Correlation of Microstructure with Embrittlement of Hastelloy B and Hastelloy B-2 Using TEM"

Kerri Winter (Junior, Duke University)

"lonic and Morphological Changes in Mg-Deficient Cultured Heart Cells"

The 1994 Undergraduate Scholarship Program is currently soliciting applications from junior and senior students interested in conducting a research project which involves the use of ANY microscopy technique. Students should be sponsored by a member of MSA. The maximum award is $\$ 2,500$. Application deadline has been extended to December 30,1993 .

Applications can be obtained from the MSA Business Office at Tel: (800)538-3672 or FAX (508)548-9053. If you have questions or require additional information regarding the program, please contact the following:

Dr. R.M. Albrecht: Tel.: (608)263-3952/4162, Fax: (608)262-7420

Dr. R.L. Ornberg: Tel:: (314)694-1184, Fax: (314)694-6727

\section{AT-YOUR-SITE TRAINING}

Custom, SEM, IC Metrology, Vacuum, Surface Analysis (SAM, SIMS, RBS)

\section{TRAINING ON TAPE}

Vacuum, SEM, EDS

Anthony D. Buonaquisti Ph.D. PO Box 2384

Chapel Hill, NC 27515

Call (919) 967-0129
EMC SERIES MAGNETIC FIELD COMPENSATION SYSTEMS

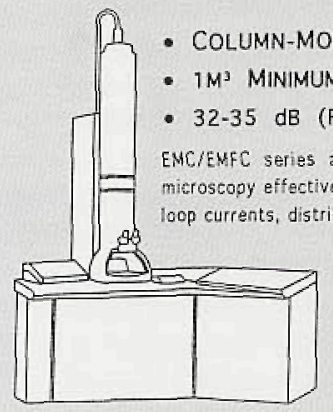

\section{SYSTEM}

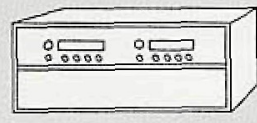

5244 Perry City Road - Trumansburg NF 14886 + (607)587.5411 + for (607)587.7806

LINEAR Research Associates

\section{SMILEYS, ANYONE?}

Smile: Some people definitely have too" much time on their hands. What started out as a simple happy face, or smiley, tacked on to messages in computer billboards and networks has now grown into a pseudolanguage made up of more than 600 icons, called emoticons. Two recently published dictionaries, Seth Godwin's "The Smiley Diectionary" and David Sanderson's "Smileys," provide some guidance. When reading the icons, you need to do two things: Look at them sideways and be generous in your interpretations.

Some commonly used symbols:

Happiness : - )

Wink $;-$ )

Sympathy :'-l

Befuddlement $\left.\frac{\text { o }}{-}-\right)$

Shocked and amazed :-0

A kiss :-*

Some famous foks have even gotten an icon of their own:

:0) for clinton

$8(:-)$ for Mickey Mouse

$8(:-) 8$ for Annette Funicello

:-)-! for Hank Aaron

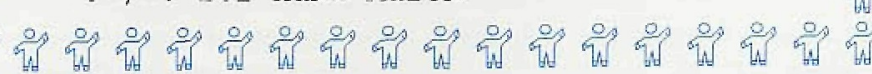

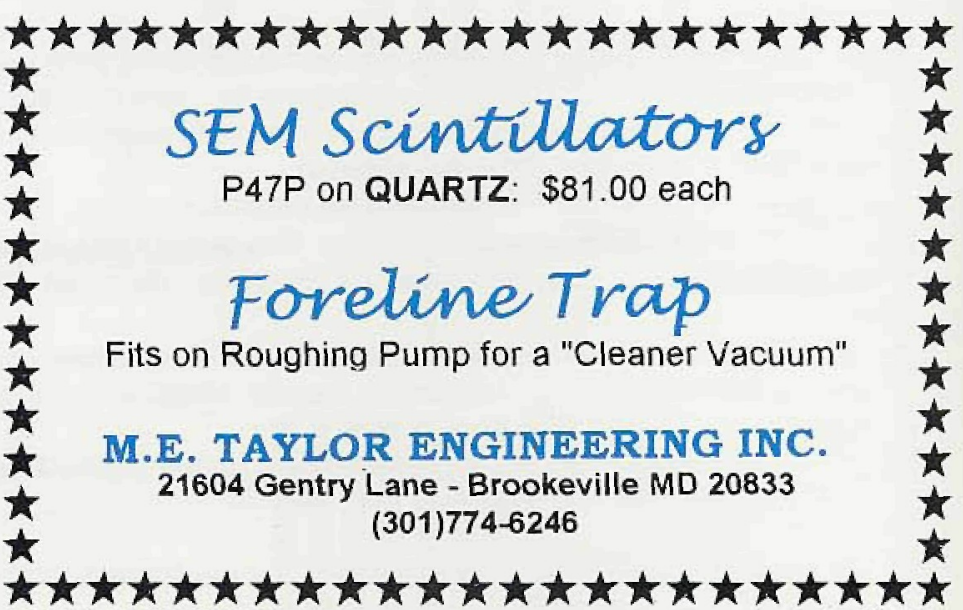

